\title{
Instituciones crediticias no bancarias del Porfiriato: Almacenes generales de depósito, Casas de empeño y Cajas de ahorro
}

\author{
Non-Bank Credit Institutions during the Porfiriato: \\ Warehouses, Pawn Shops and Saving Associations
}

\author{
Iliana Marcela Quintanar Zárate \\ Centro de Investigación y Docencia Económicas \\ División de Historia \\ Ciudad de México, México \\ iliana.quintanar@cide.edu
}

\begin{abstract}
Resumen
La historiografía sobre la banca y el crédito en México durante el Porfiriato se ha concentrado mayoritariamente en analizar el impacto del sistema bancario en el desarrollo de la economía y el proceso de industrialización acontecido en las últimas décadas del siglo XIX y primera del XX; así como en la identificación de los orígenes de la banca central, mediante el estudio del papel del Banco Nacional de México como agente financiero del gobierno. Con ello ha quedado al margen el análisis de algunas instituciones crediticias no bancarias que también operaron en el periodo, tales como los almacenes generales de depósito, las casas de empeño y las cajas de ahorro que tuvieron un importante papel en el financiamiento al comercio y al consumo. El presente artículo tiene como objetivo conocer el proceso de formación de aquellas instituciones para aportar al conocimiento de las distintas formas de crédito desarrolladas durante el Porfiriato.
\end{abstract}

Palabras clave: Porfiriato; crédito; banca

Cómo citar este artículo/ How to cite this article: Quintanar Zárate, I. M. (2021). Instituciones crediticias no bancarias del Porfiriato: Almacenes generales de depósito, casas de empeño y cajas de ahorro. Revista de Historia Americana y Argentina, 56 (1), pp. 173-200. https://doi.org/10.48162/rev.44.005 


\begin{abstract}
The historiography of banking and credit institutions during the Porfiriato has focused primarily on the analysis of the banking system's impact on the development of the Mexican economy, as well as on the country's industrialization across the last decades of the nineteenth and the beginning of the twentieth centuries; secondly, it has pointed out the origins of central banking through the study of the role that the National Bank of Mexico played as the government financial representative. That perspective has put aside the analysis of some of the non-banking credit institutions that operated at the same time, for example, warehouses, pawnshops, and saving associations, which, as a whole, also had an important role in funding commerce and trade. This article aims to reveal the process that helped create those non-banking institutions, in order to deepen our understanding of the different ways in which credit was developed during the Porfiriato.
\end{abstract}

Key words: Porfiriato, credit, non-bank institutions

Recibido: 15/09/2020 Aceptado: 8/01/2021

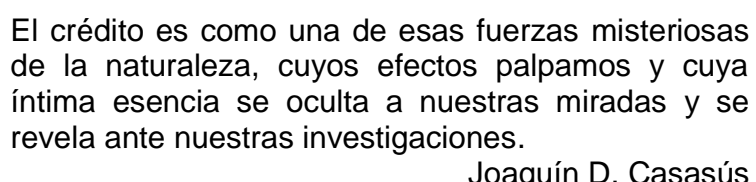

El sistema bancario mexicano se consolidó en las últimas décadas del siglo XIX en buena medida por los cambios institucionales que, al reglamentar el tipo de bancos y sus operaciones, pretendían promover las principales actividades económicas (agricultura, comercio, industria). Si bien el establecimiento de nuevas y modernas instituciones bancarias influyó en una mayor disponibilidad de capitales susceptibles de ser invertidos, lo cierto es que su aparición no necesariamente desplazó a las tradicionales formas de crédito tales como las casas mercantiles, las sociedades cooperativas y las casas de empeño.

Carlos Marichal y Gustavo A. del Ángel han señalado que en los últimos años los estudios referentes a la historia de la banca y el crédito ha crecido considerablemente. Marichal destaca que en aquellos análisis ha predominado el estudio del Banco Nacional de México, su proceso de 
formación y su relación con el gobierno mexicano. Al mismo tiempo que en los últimos años ha habido una producción importante sobre la formación, administración e influencia de la banca regional en algunos estados de la república como Veracruz, Estado de México, Durango, Jalisco, Sinaloa, Nayarit, Aguascalientes, Baja California y Puebla (Marichal y Del Ángel, 2003). Si bien la historiografía de la banca decimonónica es extensa, lo cierto es que poco se ha estudiado el origen y desarrollo de algunas instituciones crediticias no bancarias que coexistieron con la banca regional y nacional. De ahí pues que el objetivo del presente artículo es analizar las instituciones de crédito no bancarias dirigidas a financiar el comercio y el consumo popular, es decir, los almacenes generales de depósito, las casas de empeño y las cajas de ahorro. El texto está dividido en tres apartados, el primero se centra conocer las características de las instituciones bancarias antes de la publicación de la Ley General de Instituciones de Crédito de 1897 y posteriormente conocer las características del sistema bancario establecido por aquella legislación. El segundo y tercer apartado analizan las características de los almacenes generales de depósito, las casas de empeño y las cajas de ahorro.

\section{Banca y Crédito en el México Porfiriano}

El mercado de capitales en México tuvo un lento desarrollo durante el siglo XIX a causa de la inestabilidad política, el bajo ingreso per cápita y las restricciones institucionales. Estos factores fueron enfrentados por mineros, hacendados y comerciantes mediante la petición de préstamos a fuentes informales de crédito, casas mercantiles o agiotistas, quienes generalmente realizaban préstamos a corto plazo con elevadas tasas de interés (Marichal, 2007, pp. 84-85). El crédito parabancario, es decir aquel que se otorgaba previo establecimiento de los bancos, estuvo dominado por comerciantes banqueros que realizaban operaciones de compra-venta y descuento de letras de cambio, letras comerciales emitidas por exportadores e importadores; el adelantamiento de créditos mercantiles y refaccionarios a otros comerciantes, industriales 0 agricultores y finalmente a la administración de fortunas de otros empresarios que generalmente radicaban fuera del país (Marichal, 1999, pp. 774-776).

Mario Cerutti (1994) señala que en los estados norteños del país, el crédito parabancario estaba dominado en grandes familias que acumularon parte de su fortuna en la primera mitad del siglo XIX y que al advertir el crecimiento de algunas actividades económicas, como la manufacturera, 
decidieron invertir sus capitales en ellas. El mismo autor menciona que una de las principales características del crédito parabancario es que en su mayoría otorgaba préstamos en mercancías -lo que permitía colocar e invertir la producción de haciendas, ranchos y negociaciones comercialespor lo que estas empresas familiares se convirtieron en habilitadoras de la industria y la agricultura. El otorgamiento de crédito por esta vía ya fuese en mercancías o efectivo, dependía en buena medida de la pertenencia a redes de parentesco y paisanaje que limitaban el acceso a los capitales disponibles solo a los miembros de la élite regional. De esa manera, a partir de la década de 1870, las casas mercantiles regiomontanas se caracterizaron por desarrollar tareas que suplían la ausencia de un sistema bancario (Cerutti, 1994, p. 195). En Monterrey, las casas mercantiles que ejercieron sus actividades prestamistas previo al establecimiento de los bancos eran la Hernández Hnos. Sucesores y la Patricio Milmo e Hijos que invirtieron sus capitales en la agricultura, ganadería e industria pesada.

El predominio de las casas mercantiles en actividades prestamistas de hecho fue el común denominador del sistema de crédito en distintos estados de la república como Campeche, Veracruz, Monterrey, Sonora y Durango. Estas instituciones solían dotar de capitales a haciendas, ranchos, industrias o minas, pagaderos con su propia producción, por lo que fungieron como intermediarias financieras habilitadoras de la agricultura, la industria y el comercio (Cerutti, 1999, pp. 298-315).

Cabe destacar que el crédito ofertado por las casas mercantiles no desapareció con el establecimiento de bancos bajo los lineamientos de la Ley General de Instituciones de Crédito de 1897, incluso era muy común que coexistieran. Gustavo Aguilar muestra que, en Sinaloa, previo al establecimiento de la sucursal del Banco de México en 1889, quienes realizaban operaciones de crédito, cambios y depósitos eran las casas comerciales que otorgaban préstamos a todas las actividades económicas, al gobierno estatal y a los ayuntamientos. Generalmente aquellos créditos se realizaban con garantía hipotecaria, pactos de retroventa o contratos en anticrecis, ${ }^{1}$ por lo que en caso de incumplimiento por parte del acreedor los bienes hipotecados pasaban a propiedad de los prestamistas (Aguilar, 2003, p. 52). El estudio sobre la banca sonorense de Ana Isabel Grijalva Díaz

${ }^{1}$ Contrato en el que el deudor consiente que su acreedor goce de los frutos de la finca que le entrega, hasta que sea cancelada la deuda. Diccionario de la lengua española. Disponible en línea: https://dle.rae.es/anticresis

RHAA v.56 n.1, 2021. ISSN: 0556-5960, ISSNe 2314-1549. CC BY-NC-SA 4.0 
muestra que los "antiguos prestamistas", aun cuando formaron parte de los accionistas del Banco de Sonora, continuaron con el otorgamiento de efectivo o en especie a cambio de una parte o el total de los bienes del prestatario que en caso de incumplimiento podía perderlos. Los mecanismos de crédito más comunes utilizados por los prestamistas sonorenses fueron el pacto de retroventa, de muto con garantía hipotecaria y cuenta corriente, siendo los dos últimos los más socorridos por los prestatarios debido a las facilidades de pago, la liquidez disponible y el bajo riesgo de perder las propiedades garantizadas. El estudio de Grijalva Díaz muestra también que el crédito informal presentaba un alto grado de concentración y especialización. El primero porque en el periodo de 1890 a 1902 solo seis prestamistas otorgaron en préstamo un capital de \$868 584 que correspondió al $60 \%$, lo que revela un control del mercado de capitales en la elite local. La especialización se refiere a que los principales prestamistas diversificaron poco sus inversiones y se concentraron mayoritariamente en un ramo, así Ramón Corral y la familia Echeverría se dedicaron a habilitar tierras de labor o ranchos, mientras que las casas comerciales de Pedro Cosca, José García y Roldán y Honrado por naturaleza propia de sus negocios se dedicaron a financiar actos comerciales y habilitar tierras dedicadas al cultivo de cereales (Grijalva Díaz, 2016, pp. 117-123).

El caso de Yucatán estudiado por Juliette Levy (2012) muestra el papel de intermediación financiera que jugaron los notarios en la articulación del mercado de capitales en el estado. Previo a la inauguración de bancos en la región, los comerciantes colocaban capitales en la agricultura mediante cartas de crédito, pagarés y otros instrumentos a corto plazo. Debido al boom henequenero de la zona, ${ }^{2}$ la necesidad de crédito se hizo apremiante por lo que hacia la década de los años ochenta se establecieron algunas instituciones bancarias como una sucursal del Banco Nacional de México, el Banco Mercantil de Yucatán y el Banco Yucateco, cuyos principales accionistas eran los dueños de las casas mercantiles locales. Dado que aquellos se trataban de bancos de emisión, no podían realizar operaciones hipotecarias y aun cuando después de 1897 se estableció el Banco Hipotecario de Yucatán y Campeche, no constituyó una fuente significativa

\footnotetext{
${ }^{2} \mathrm{El}$ boom henequenero se refiere a los elevados índices de producción de henequén a finales del Porfiriato. La fibra natural era utilizada para la elaboración de sogas y sacos que apoyaron los procesos de exportación de materias primas en América y Europa.
}

RHAA v.56 n.1, 2021. ISSN: 0556-5960, ISSNe 2314-1549. CC BY-NC-SA 4.0 
de crédito ( $\mathrm{pp}$. 46-47). Frente a la existencia de bancos formalmente establecidos, Levy refiere que el crédito hipotecario a largo plazo continuó bajo la figura de crédito personal, ya que tenía la ventaja de asegurarse con una garantía y registrarse notarialmente, lo que le daba mayor confianza al público usuario.

Los estudios sobre el crédito parabancario y la subsistencia de ciertas formas de crédito que no pasaban por las instituciones formales muestran que aun con el establecimiento de un sistema bancario moderno, la población seguía acudiendo a sus tradicionales formas de obtención de capitales de inversión. Cabe destacar que era común que los propios fundadores de los bancos, en su mayoría dueños de casas mercantiles mexicanos y extranjeros, no abandonaran aquellas prácticas por lo que controlaron el mercado de dinero formal e informal. Así, como refieren Leonor Ludlow (2003), Jaime Olveda (2003) y María Eugenia Romero Ibarra (2003), aun cuando los comerciantes-banqueros de los estados de Veracruz, Estado de México y Jalisco se integraron a las mesas directivas de las sucursales del Banco Nacional de México o del Banco de Londres y México, e incluso establecieran bancos por sí, esto no implicó el cese de sus actividades crediticias al margen del sistema bancario hasta el momento existente. María Guadalupe Rodríguez López (2003) menciona que incluso la estructura de las casas de comercio y préstamo resultaron muy funcionales tanto para el apoyo a la actividad económica como a los bancos nacionales, pues estos en no pocas ocasiones echaron mano de sus redes y circuitos mercantiles.

Si bien el primer banco en México, el Banco de Londres, México y Sudamérica, se estableció en los años sesenta del siglo XIX su radio de acción se limitó en sus primeros años de operación a la ciudad de México. Los estados que llevaron la batuta en la creación de instituciones crediticias que convivieron con las casas mercantiles fueron Chihuahua y Monterrey. De esa manera se crearon el Banco de Santa Eulalia (1878), el Banco Mexicano (1878) y el Banco Minero de Chihuahua (1882) entre otros, instituciones reguladas por los contratos firmados con los gobiernos de los estados correspondientes (Gurza, 1905).

La publicación del Código de Comercio de 1884 implicó cambios importantes en la banca mexicana, ya que el artículo 640 regulaba sus operaciones en tanto se publicaba una ley para tal efecto. Con aquel nuevo ordenamiento, y debido a la ayuda ofrecida al gobierno para superar la crisis económica de ese año, el Banco Nacional de México recibió el encargo de 
manejar la deuda, abrirle una cuenta corriente al gobierno por $\$ 4000000$ con un interés de $6 \%$, y las facultades de emitir y circular billetes por el triple de la cantidad en efectivo y barras de metal en caja de curso forzoso en las oficinas del gobierno. Entre los privilegios cedidos se encontraba la no cesión de nuevas concesiones de bancos de emisión. Tres años después, el Banamex se fortaleció con la fusión con el Banco Mercantil Mexicano (Ludlow, 1998). En 1881 también se estableció el Banco Hipotecario Mexicano, al que se le otorgaron los privilegios de exención de impuestos a su capital, acciones, bonos, escrituras y edifico, así como la exclusividad en su ramo (Secretaría de Hacienda y Crédito Público - en adelante SHCP-, 1900 , t. II).

Los privilegios otorgados al Banamex, ratificados en el Código de Comercio de 1884, estaban en contraposición con las concesiones de los bancos existentes, de ahí que se suscitara una disputa entre quienes defendían a la institución y quienes opinaban que debía ceder algunos de sus privilegios (Ludlow, 2006, pp. 36-41). En aras de dar una solución al conflicto entre banqueros, el gobierno obtuvo la autorización en 1888 para dar concesiones para el establecimiento de bancos, lo que promovió la renegociación de privilegios con el Banco de Londres y México (que cambió de denominación y recibió la autorización para emitir billetes mediante la compra del Banco de Empleados) y el Banco Hipotecario Mexicano, así como el surgimiento de varios bancos en los estados de la república con concesión federal.

La falta de uniformidad en los contratos de concesión, junto con la necesidad de formalizar un sistema financiero fueron los catalizadores para elaborar la Ley General de Instituciones de Crédito en 1897. Previa renegociación con las mesas directivas de los bancos existentes sobre la ampliación de sus privilegios, en términos generales, el ordenamiento estableció un sistema de pluralidad bancaria (Macedo, 1905, pp.153-162). Sin perder prerrogativas como la emisión de billetes y su aceptación a nivel nacional, el Banamex continuó con sus actividades de banca de gobierno (sin ser propiamente del gobierno ya que su capital era privado) y aceptó la fundación de bancos al interior del país (Maurer, 2002, pp. 40-43).

El sistema bancario surgido de la Ley de 1897 (SHCP, 1909) estaba integrado por tres tipos de instituciones: los bancos de emisión, refaccionarios e hipotecarios. Las concesiones de todos los bancos se otorgarían sólo a sociedades anónimas y su duración sería de treinta años para los de emisión y cincuenta para los refaccionarios e hipotecarios contados a partir de la publicación de la ley. En cuanto a las facultades de 
cada banco, los de emisión quedaban autorizados a realizar operaciones de crédito y descuento a plazos cortos, a emitir moneda cuyo monto estaba limitado al doble de existencia en caja y al triple de capital social efectivamente pagado, y tenían prohibido hacer préstamos hipotecarios.

Los bancos hipotecarios estaban autorizados a emitir bonos hipotecarios cuyo importe no debía exceder lo otorgado en préstamos con garantía hipotecaria (fincas rústicas o urbanas) y reembolsados por sorteos. Estos bancos podían invertir sus fondos en la adquisición de sus propios bonos, hacer préstamos a plazos de seis meses con garantía de títulos o valores, recibir depósitos en cuenta corriente; girar, comprar y vender distintos títulos de crédito y hacer préstamos o anticipos para obras de mejoramiento público.

Finalmente, los bancos refaccionarios estaban dedicados a cubrir los gastos de explotación sin necesidad de poner en garantía la propiedad. Estaban facultados a hacer préstamos en numerario a plazos no mayores de dos años a negociaciones mineras, industriales y agrícolas, a prestar su garantía para facilitar el descuento de pagarés exigibles a un plazo máximo de seis meses y a emitir bonos de caja causantes de réditos y reembolsables a plazos de tres meses a dos años.

La ley promovió entonces el establecimiento de los bancos de Coahuila, San Luis Potosí, Occidental de México (Sinaloa), Sonora y Veracruz, entre muchos otros a lo largo del régimen Porfiriano (Gómez, 2011, p. 2076). Al respecto, Mónica Gómez menciona que el nuevo ordenamiento trajo consigo

(...) una disminución de la incertidumbre respecto a la observancia de los derechos de propiedad otorgados a los agentes económicos en la concesión, un ahorro de los costos vinculados con la negociación entre los agentes privados y el Estado para establecer los acuerdos institucionales y una disminución de los costos de monitoreo de las normas (Gómez, 2003, p. 329).

Las investigaciones dedicadas al estudio de los bancos estatales muestran que en general tuvieron un impacto favorable en la ampliación del crédito, sin embargo, también destacan que el acceso al mismo estaba limitado a las redes clientelares, de parentesco, negocio y paisanaje (Cerutti y Marichal, 2003). Noel Maurer y Stephen Haber (2007) refieren que el insider lending -el préstamo de los fondos bancarios a los miembros de sus mesas 
directivas o a su parientes- fue una práctica muy difundida en la época y su finalidad era aminorar algunos riesgos, tales como la falta de información financiera sobre los posibles sujetos de crédito y la falta de seguridades sobre los derechos de propiedad, al tiempo que fungía como táctica de reforzamiento sobre los montos otorgados y sus garantías a personas de conocida solvencia.

Si bien la ley de 1897 estableció un sistema bancario moderno plural, a decir de Enrique Martínez Sobral esto no significaba que aquellas tres clases de bancos eran las únicas que podían existir. De hecho, hacia 1910 en México existían varios bancos de depósito nacionales y extranjeros, algunos constituidos en forma de sociedad anónima y otros en sociedad colectiva o comanditaria e inclusos algunos de un solo dueño. Este tipo de instituciones no contaron con una legislación especial durante el Porfiriato, por lo que actuaban según los lineamientos establecidos para ese tipo de sociedades en el Código de Comercio ya mencionado. Para Martínez Sobral era preciso ocuparse de estas instituciones de crédito particulares, ya que movilizaban un capital aproximado de nueve millones de pesos y, a diferencia de los bancos legalmente constituidos por la Ley General de 1897, no ofrecían seguridades de los depósitos a sus deudores, pues aquellos solo representaban en parte a la moneda y no tenían un motivo de necesidad que obligara a sus títulos a permanecer en circulación ${ }^{3}$.

A decir de Martínez Sobral, billetes y depósitos generaban distintas obligaciones y compromisos del banco y los deudores, siendo los segundos más riesgosos pues aquel que saldaba deudas con billetes no era necesariamente un fiador del banco, mientras que aquel que lo hacía con cheques no se liberaba de sus obligaciones con la institución sino hasta que el girado cubriera el importe. A partir de la quiebra de varios bancos de depósito y la pérdida de capitales de "ricos y pobres", el autor mencionaba que las autoridades competentes debían establecer ciertas regulaciones que no contravinieran el principio de libertad bancaria que operaba en el país pero que al mismo tiempo tuviese en cuenta las características y circulación de los depósitos o cheques que "por endoso o mera tradición circula de mano en mano"4.

${ }^{3}$ El Economista Mexicano (en adelante EEM), México, 19-03-1910, p. 421.

${ }^{4}$ EEM, 19-03-1910, p. 401. 
La reflexión de Martínez Sobral da cuenta que aun cuando la ley de 1897 intentó consolidar el sistema bancario a partir de la dotación de prerrogativas y exenciones para darles mayor seguridad a sus operacionescuyo efecto esperado era el cultivo de la confianza entre el público deudorseguían existiendo otras instituciones de crédito. Aquellas otras instituciones, aun cuando ofrecían pocas o nulas seguridades, quedaron al margen de la ley y movilizaron capitales de importancia entre la población.

El sistema crediticio durante el Porfiriato entonces estaba compuesto por diversas instituciones financieras que oscilaron entre la modernización y la permanencia de fuentes de financiamiento tradicionales. La pérdida de importancia de la Iglesia como principal prestamista en las primeras décadas del siglo XIX promovió el surgimiento de casas mercantiles que desplegaron actividades crediticias, con dinero en efectivo o mediante la figura de la habilitación, para la diversificación de sus propias negociaciones. Dado que las casas mercantiles promovieron la dinamización de la economía en algunos espacios, no desaparecieron del todo con el establecimiento de bancos modernos, con y sin concesión del gobierno, por varias razones. Primero porque debido a que el acceso a sus capitales dependía de redes de negocios vinculadas por parentesco o paisanaje entre los miembros de sus mesas directivas, las casas mercantiles resultaron entonces una opción viable para todos aquellos que no pertenecieran a la red. Segundo porque debido al crecimiento acelerado de la economía con la explotación de nuevas minas y el establecimiento de negocios mercantiles e industriales, el sistema bancario formal no tenía la capacidad de atender todas sus necesidades. De ahí pues que las casas mercantiles tuviesen un papel de complementariedad del sistema bancario en aras de cubrir la demanda local o estatal de crédito. Aquello sumado a la concentración del crédito una vez que se legalizó un nuevo sistema bancario plural con la Ley General de Instituciones de Crédito de 1897.

\section{Una nueva figura crediticia: los Almacenes generales de depósito.}

El comercio exterior fue uno de los sectores claves para el crecimiento de la economía mexicana durante el Porfiriato. Sandra Kuntz (2007) menciona que el crecimiento de las exportaciones en las últimas décadas del siglo XIX promovió la salida del estancamiento económico e imprimió de dinamismo a la economía nacional, pues impulsó el ahorro y la inversión productiva generando externalidades positivas para el crecimiento de otros sectores. El

RHAA v.56 n.1, 2021. ISSN: 0556-5960, ISSNe 2314-1549. CC BY-NC-SA 4.0 
auge exportador se debió a diversos factores como los cambios institucionales que favorecieron la inversión, el desarrollo de la infraestructura ferroviaria y la llegada de capitales extranjeros que promovieron la incorporación de recursos ociosos a la producción en gran escala (Kuntz, 2007, p. 336). Si bien buena parte de las exportaciones mexicanas provenían de la minería, incluidos los metales preciosos en pasta y amonedados, Kuntz advierte que la composición de la canasta exportadora mexicana era diversa pues incluyó también productos tropicales (henequén, café), agropecuarios (ganado, cueros y pieles) y forestales (maderas ebanistería).

El boom exportador provocó cambios en la legislación aduanal y en el sistema crediticio para apoyar al sector. De ahí la publicación de la Ordenanza de aduanas de 1891, la Ley de Organización de aduanas de 1893 (Dublán y Lozano, 1898a, p. 459-471) y el establecimiento de la Dirección General de Aduanas en 1900 (Dublán y Lozano, 1904, p. 134) que en conjunto pretendían dotar de reglas claras y precisas al servicio aduanal. Este proceso estuvo acompañado con la habilitación de algunos puertos para el comercio internacional y la mejora de su infraestructura. De esa manera, en la década de los noventa, el secretario de Hacienda José Yves Limantour autorizó la construcción de almacenes generales en los puertos de Guaymas y Veracruz, para mejorar el mal estado en el que se encontraban los edificios y reducir el peligro de robo o maltrato de las mercancías en los cobertizos provisionales ${ }^{5}$. Estos almacenes no eran considerados hasta el momento como una fuente de crédito para el comercio, no obstante, el crecimiento acelerado de las transacciones en los puertos obligó a que los certificados de depósitos emitidos por el pago de almacenaje fuesen utilizados como títulos de crédito vía el endoso.

Debido a que los almacenes generales realizaban operaciones de crédito, su reglamentación fue materia de discusión dentro de la Comisión nombrada para elaborar la Ley General de Instituciones de Crédito de 1897. La cual decidió que mientras se elaboraba una ley particular, estos quedarían sujetos a las reglas del capítulo $2^{\circ}$, título IV, libro II del Código de Comercio -que en lo general establecían las condiciones de los certificados y bonos emitidos 6 - por el que quedaban autorizados únicamente a realizar

\footnotetext{
${ }^{5}$ Archivo José Yves Limantour (en adelante AJYL), Carta de José Yves Limantour a Javier Arrangoiz, México, 9-12-1898, CDLIV.1a.1883.4.

${ }^{6}$ Diario Oficial de la Federación, 07-10-1889, pp. 585-586.
}

RHAA v.56 n.1, 2021. ISSN: 0556-5960, ISSNe 2314-1549. CC BY-NC-SA 4.0 
préstamos en efectivo o con garantía de las mercancías recibidas. En el proyecto de ley entregado, se determinó que sólo se podrían establecer almacenes en el país con un capital exhibido de $\$ 100000$ y que incluso podían emitir billetes en las mismas condiciones que los bancos de emisión. En la versión final de la Ley General se decidió que los almacenes generales de depósito, los bancos prendarios y las cajas de ahorros quedarían sujetos al artículo 640 del Código de Comercio, que a la letra mencionaba:

(...) las instituciones de crédito se regirán por una ley especial, y mientras éstas se expide, ninguna de dichas instituciones podrá establecerse en la república sin previa autorización de la Secretaría de Hacienda y sin el contrato respectivo aprobado, en cada caso, por el Congreso de la Unión (Diario Oficial de la Federación, 07-10-1889, p. 613).

Es decir, para efectos legales si bien los almacenes generales de depósito existían físicamente en las aduanas y emitían algunos títulos, no se les reconoció formalmente como instituciones crediticias sino hasta el periodo de reforma aduanal en 1900.

De esa manera, en uso de las facultades cedidas al ejecutivo el 3 de junio de 1897 para la reglamentación de las instituciones de crédito, el 16 de febrero de 1900 fue expedida la "Ley de Almacenes de Depósito" en la que definía que sus principales funciones eran el resguardo, conservación y custodia de mercancías nacionales o extranjeras. A cambio de lo cual podían emitir dos recibos, un certificado de depósito y un bono de prenda, utilizados por los comerciantes para negociar con las mercancías sin necesidad de trasladarlas de un lugar a otro. De tal forma que los objetivos de estas instituciones eran

(...) ahorrar los gastos de transporte que ocasionan las mercancías cada vez que pasan del poder de uno a otro comerciante, y facilitar, por medio de la creación de los títulos que emiten, la práctica de todas las operaciones que con ellas pueden ejecutarse (Casasús, 1890, p. 271).

La ley mencionaba claramente en el artículo 2 que al ser considerados como instituciones de crédito les eran aplicables todas las disposiciones y franquicias que otorgaba la ley de 1897. Fueron establecidos dos tipos de almacenes, los que recibieran mercancías nacionales y extranjeras nacionalizadas mediante el pago de los derechos correspondientes y

RHAA v.56 n.1, 2021. ISSN: 0556-5960, ISSNe 2314-1549. CC BY-NC-SA 4.0 
aquellos que además recibieran mercancías extranjeras que no hubiesen pagado derechos. Si bien el primer tipo se podía establecer en todo el país, del segundo tipo sólo podían establecerse en la Ciudad de México y las aduanas marítimas y fronterizas.

De la misma manera que los bancos de emisión, hipotecarios y refaccionarios, las concesiones para el establecimiento de los almacenes sólo las podía otorgar el ejecutivo, en su caso por un periodo de cuarenta años a sociedades establecidas con un mínimo de $\$ 500000$ de capital. Si bien los certificados y los bonos quedarían exentos de impuestos, los dueños de los almacenes quedaban como responsables del pago de los impuestos de mercancías que no lo hubiesen realizado. En cuanto a la vigilancia, la ley mencionaba que el número de guardalmacenes, comisarios y personal correspondiente sería determinado según cada concesión. Finalmente, sobre las tarifas de almacenaje, la Secretaría de Hacienda se arrogaba la facultad de autorizarlas previa revisión (Dublán y Lozano, 1904, pp. 121-124).

Si bien los almacenes generales de depósito hacían operaciones de crédito útiles para el comercio, ya que una de sus funciones era la pignoración, durante el Porfiriato sólo se establecieron tres de manera formal en los puntos mercantiles más importantes del país, la ciudad de México, Veracruz y Progreso. Hacia 1902, la Secretaría de Hacienda otorgó una concesión a los Bancos Central Mexicano, Banco Mercantil de Veracruz y la Compañía Banquera Anglo Mexicana para establecer en un radio de 50 kilómetros almacenes de depósito en las ciudades de México y Veracruz (SHCP, 1905, pp. 153-157). La unión de las tres instituciones aseguró el establecimiento de los almacenes con un fuerte capital inicial de $\$ 2000000$, de los cuales el gobierno retendría $\$ 200000$ en bonos de $3 \%$ de la deuda consolidada o $\$ 150000$ en bonos del $5 \%$ de la deuda interior amortizable. Si bien la concesión tendría una duración de 40 años contados a partir de la ley general de 1897, en la concesión se consignaba que los banqueros disfrutarían durante 25 años de las franquicias y exenciones de impuestos otorgadas por dicha ley. Exenciones impositivas que eran extensivas a los materiales utilizados en la construcción de los edificios.

Sobre las tarifas, el contrato mencionaba que quedaban sujetas a aprobación de la Secretaría de Hacienda y si bien no debían establecerse tarifas especiales a ninguna persona o compañía, el gobierno gozaría de un descuento mínimo de $25 \%$ y máximo de $50 \%$ sobre los precios de la tarifa para el público. Si bien la Secretaría quedaba facultada para autorizar 
derechos sobre ciertos artículos por volumen, número de piezas o espacio superficial, estableció que para cada clase de artículos extranjeros correspondía una tarifa que oscilaba entre los $\$ 0.08$ y los $\$ 0.30$.

Una vez establecidas las reglas para las tarifas, resalta que en el contrato de concesión se autorizó a la Compañía tripartita la emisión de bonos hipotecarios o cualquier otra obligación con garantía de los edificios de su propiedad construidos en sus propios terrenos; solo si se dejaba libre de todo gravamen valores equivalentes al capital social, el plazo de redención de los bonos no excediera la duración del contrato, el gravamen no excediera del $50 \%$ de la propiedad gravada. Sobre los edificios de los almacenes, el contrato establecía la superficie de construcción y dejaba a los dueños la responsabilidad tanto de los derechos causados por las mercancías como el importe de las multas y demás responsabilidades pecuniarias en que hubiesen incurrido los mismos dueños o consignatarios. Para asegurar el establecimiento de los almacenes, el gobierno estableció un contrato de arrendamiento de los terrenos cercanos a las oficinas aduanales de Santiago de Tlatelolco en la Ciudad de México.

Finalmente, debido al giro de los establecimientos, quedaban sujetos a las leyes generales de aduanas marítimas y fronterizas así como a los reglamentos y otras disposiciones que se decretaran relativas a la ley general sobre almacenes generales de depósito. Cabe mencionar que, si bien los principales accionistas de la Compañía concesionaria eran tres bancos, el Central Mexicano, el Mercantil de Veracruz y la Compañía Banquera Anglo-Mexicana, también contó con accionistas individuales que juntos exhibieron el capital social de \$2 000000 en dos años (Barrera Lavalle, 1909, p. 148).

El mismo año de 1902 se otorgaron concesiones en los mismos términos que el ejemplo anterior a la Compañía del Ferrocarril, Muelle y Almacenes de Progreso S. A. y a la Compañía del Ferrocarril de Mérida a Valladolid para el establecimiento de almacenes generales de depósito en puerto Progreso (Barrera Lavalle, 1909, pp. 160-163, 166-169). El establecimiento de los almacenes de la ciudad de México, el puerto de Veracruz y Progreso atendían a las necesidades del comercio de crédito en el contexto de auge del sector externo que ya se ha comentado con anterioridad. Esto porque las tres localidades eran los nodos mercantiles de las zonas Centro, Pacífico y Sureste del país. 
El establecimiento de almacenes generales de depósito, sobre todo aquellos del segundo tipo que estaban facultados a recibir mercancías extranjeras que no hubiesen satisfecho los derechos fiscales correspondientes, fue objeto de muchas críticas. En principio porque aquella prerrogativa implicaba veladamente la cesión de un monopolio de las importaciones de mercancías extranjeras a las compañías concesionarias; y en seguida porque el almacenaje de mercancías debía ser un servicio ofrecido por el Estado que al concederlo a particulares se eximía de sus responsabilidades. Al respecto, Francisco Barrera Lavalle (1909) mencionaba que las críticas eran infundadas pues en la ley no sólo se establecían las previsiones necesarias para asegurar los intereses del fisco y para evitar el movimiento monopólico de las importaciones; sino que, consecuente con el pensamiento liberal de la época, los críticos obviaban el hecho de que la libertad individual era un factor de beneficio para la sociedad entera.

Frente a las críticas, los almacenes generales de depósito fungieron como una nueva institución crediticia cuyo objetivo era promover la movilización de las mercancías de importación al interior del territorio mexicano mediante el resguardo, para su negociación, en instituciones administradas por particulares. En ese sentido, ofrecían al sector externo una alternativa crediticia complementaria al sistema bancario pues, la Compañía de Almacenes Generales de Depósito de México y Veracruz movilizó capitales de importancia en bonos de prenda, ya que en el periodo de 1902 a 1907 el monto de este rubro creció significativamente de 94264.25 a 1181449.22 de pesos (Barrera Lavalle, 1909).

\section{El crédito prendario: las Casas de empeño y las Cajas de Ahorro}

El establecimiento y consolidación del sistema bancario en México se fincó en el interés por promover las principales actividades económicas. Aquello no sólo benefició a grandes empresas y elites regionales del país, sino que dejó al margen la inclusión de instituciones crediticias dirigidas a los sectores sociales menos favorecidos, que en momentos de urgencia acudieron a las tradicionales fuentes de crédito, es decir las casas de empeño. 
La principal operación de las casas de empeño era otorgar créditos al consumo, lo que les diferencia del crédito prebancario, bancario y de los almacenes generales de depósito que en su mayoría estaban dirigidos a la habilitación 0 avío para agilizar las transacciones mercantiles. Las solicitudes de préstamo a las casas de empeño debían presentarse con una garantía o prenda, que podía ser cualquier pertenencia de cierto valor para el deudor. Debido a la multiplicación con que estas instituciones se establecieron en la primera mitad del siglo XIX y dada la falta de un sistema de crédito popular, hacia los años setenta el gobierno trató de regular sus operaciones. De esa forma, el gobernador de la ciudad de México, Joaquín Othón Pérez, emitió en febrero de 1875 el "Reglamento de casas de empeño" con la finalidad de establecer tanto lineamientos generales de estas instituciones de crédito, como evitar abusos por parte de los dueños (Dublán y Lozano, 1882, pp. 704-708).

El Reglamento de 1875 estableció que para fundar una casa de empeño era necesario contar con licencia del gobernador del distrito, así como otorgar una fianza de dos comerciantes por el triple de la cantidad a invertir en el giro. En caso de traspaso o traslado de la casa, el dueño debía contar con la autorización de la autoridad competente so pena de multa. Las casas estaban obligadas a llevar tres libros - de registro de las prendas recibidas, de avalúos y de contabilidad-, timbrados y autorizados por la administración de rentas municipales. Para evitar el abuso por parte de los dueños, éstos debían asentar en los boletos de empeño los datos de la prenda, así como las condiciones del contrato. Además, los valuadores de prendas debían presentar una fianza por 1000 pesos, recibirían un sueldo pagado con el $2 \%$ de sus avalúos y en caso de realizar algún avalúo a la baja del "justo precio" de la prenda se hacían acreedores a la destitución del cargo, así como a una multa de cien pesos. Los interventores de los remates, al ser nombrados por el gobernador del Distrito de entre la planta laboral, no tenían un sueldo asignado. El reglamento establecía algunas disposiciones sobre el proceso de remate de las prendas y para vigilar las operaciones de las casas autorizaba al gobernador del Distrito a efectuar visitas periódicas a través de comisionados nombrados para tal efecto.

Debido a que el gobernador estableció la presentación de una fianza inicial, determinó una serie de multas por malos manejos y avalúos, y declaró caducas las licencias de las casas de empeño existentes con la finalidad de ajustarlas al nuevo reglamento, provocó airadas quejas de los dueños. Los editores del periódico El Monitor Republicano mencionaban que las clausuras de estos establecimientos afectaban de manera directa a los

RHAA v.56 n.1, 2021. ISSN: 0556-5960, ISSNe 2314-1549. CC BY-NC-SA 4.0 
menesterosos que vivían del crédito prendario, al tiempo que la petición de la fianza por el triple del capital de la negociación iba en contra de las disposiciones que hasta el momento regulaban las casas de empeño. Los editores entonces destacaron la necesidad de estas instituciones para los sectores de la población menos favorecidos porque tenían cerradas las puertas del crédito en el Monte de Piedad, ya que en esa institución no se recibían prendas con valor menor a cuarenta o cincuenta pesos. Además, recomendaban una estricta vigilancia para evitar abusos por parte de los prestamistas, a quienes también había que garantizar su seguridad personal, ya que al parecer era bastante común el ataque a sus propiedades por parte de los deudores ${ }^{7}$.

La oposición de los dueños de las casas de empeño tuvo un efecto inmediato, pues el gobernador acordó suspender la aplicación de algunos artículos del Reglamento especialmente aquellos que trataban sobre la fianza inicial, las visitas y las medidas de los traspasos ${ }^{8}$. Aquello también incidió en la elaboración del siguiente reglamento emitido, esta vez por el presidente de la república, en junio de 1878 (Dublán y Lozano, 1886, pp. 540-545), por el que no sólo se eliminó la fianza inicial, sino que algunas multas fueron suprimidas o limitadas a un porcentaje del capital de la negociación. A diferencia del reglamento anterior, a decir del artículo transitorio de este nuevo marco legal no era necesario refrendar la licencia de las casas para ajustarse a él.

El reglamento de 1878 definió con claridad que bajo la denominación de Casa de Empeño

(...) se comprende todo establecimiento, cuyo giro principal consista en préstamos sobre prendas, 0 en cualquiera otra especie de contratos sobre alhajas $u$ otros objetos muebles cuyo dominio no se transmita al dueño de los establecimientos que los reciba, sino mediante ciertos pactos o condiciones (p. 540).

Es posible que a cambio de la eliminación de la fianza, el gobierno tuviese mayor margen de maniobra para establecer ciertas medidas de control, ya que aumentó un requisito para el establecimiento de estas casas, la patente; detalló prevenciones sobre los avalúos; asignó un sueldo de 800 pesos a los interventores de los remates para evitar contubernios entre

${ }^{7}$ El Monitor Republicano (en adelante EMR), México, 11-1-1877, p.1.

${ }^{8}$ El Pájaro Verde, México, 22-1-1877, p. 1.

RHAA v.56 n.1, 2021. ISSN: 0556-5960, ISSNe 2314-1549. CC BY-NC-SA 4.0 
éstos y los dueños de las casas, y finalmente estableció un nuevo libro talonario para el registro de todas las boletas emitidas.

El mismo mes de emitido el reglamento, nuevamente El Monitor Republicano publicó un artículo en el que se criticaba que no había tenido grandes novedades con respecto al anterior y en el que se ponía en duda su cumplimiento. A decir de la publicación, la multiplicación de las casas de empeño (a la fecha 185 en la ciudad de México) se debía a la pobreza generalizada por lo que eran

(...) la esperanza y el martirio de más de la mitad de nuestra población absoluta, las clases trabajadoras ocurren a ellas en busca de un auxilio; los pobres tienen allí fija su mirada, y esto sucede más cada día; la miseria avanza entre nosotros de una manera rápida ${ }^{9}$.

En aprovechamiento de esa necesidad, las tasas de interés resultaban ser muy onerosas, por lo que era preciso hacer cumplir el reglamento y no sólo emitirlo.

Si bien las autoridades y los críticos de las casas de empeño destacaron su utilidad entre los sectores menos favorecidos de la sociedad como un mecanismo de crédito al que podían recurrir en caso de emergencia, también resaltaron varios problemas en torno a ellas. En primer lugar, como ya se mencionó, la escasa reglamentación y la poca observancia de la misma, de ahí que en 1878 se dijera que "no es por falta de reglamento por lo que las cosas no caminan bien, casi todos nuestros gobernantes se ven acometidos de la manía de reglamentar pero en cuanto han publicado su ley se olvidan de ella"10. Era necesario entonces establecer mecanismos de vigilancia para garantizar el cumplimiento de la ley, sin embargo el periodo presidencial de Porfirio Díaz recién comenzaba y por el momento no contaba con los instrumentos de política necesarios para tal fin. En segundo lugar, el elevado costo del crédito prendario incidía todavía más en el empobrecimiento de los prestatarios pues, a decir de algunos testimonios de la época, la tasa de interés llegaba incluso al $25 \%$.

Hacia la década de los ochenta, Joaquín D. Casasús -abogado, economista y colaborador del régimen porfiriano- mencionaba que el crédito prendario si bien era ruinoso para los obreros debido a las altas tasas de interés con

\footnotetext{
${ }^{9} E E M, 21-6-1878$, p.1.

${ }^{10} E M R, 21-6-1878$, p. 1.
}

RHAA v.56 n.1, 2021. ISSN: 0556-5960, ISSNe 2314-1549. CC BY-NC-SA 4.0 
las que se otorgaban los créditos, el beneficio que pudiesen traer estas instituciones crediticias se veía ensombrecido por dos circunstancias. La primera, que el crédito prendario no era productivo, debido a que estaba dirigido al consumo no necesariamente implicaba el acrecentamiento de la riqueza del deudor, al contrario, le endeudaba y empobrecía más. La segunda, porque en realidad no existía una cultura del ahorro entre los obreros mexicanos lo que les hacía permanecer en la miseria ${ }^{11}$.

El municipio de la Ciudad de México cobraba en un primer momento una cuota fija según la categoría de la casa de empeño, sin embargo hacia el segundo semestre de 1886 decidió cobrar un 1 1/4\% mensual sobre las cantidades prestadas, que en el periodo ascendió a \$1333 796.25. A partir del cálculo entre los préstamos y las contribuciones, Casasús llegó a la conclusión de que la tasa de interés de los préstamos otorgados ascendía aproximadamente a un $10.92 \%$ mensual, que sumado a los recargos por refrendos y los costos de prácticas como los extravíos y ocultaciones, la tasa real ascendía a un $28.51 \%$ mensual $^{12}$.

Debido al empobrecimiento de los deudores que implicaba aquella alta tasa de interés, Casasús proponía como alternativa dos medidas. Por un lado, la elaboración de una ley que regulara el crédito prendario para que resultase menos oneroso y un apoyo real para los trabajadores y, por otro lado, la creación de cajas de ahorro.

Si bien las recomendaciones de Casasús no fueron materializadas en la inmediatez, lo cierto es que no cayeron en oídos sordos. Hacia noviembre de 1886 la secretaría de Gobernación publicó un nuevo reglamento sobre las casas de empeño que no sólo regulaba las actividades crediticias, sino que hacía mayor hincapié en la vigilancia sobre las mismas.

El reglamento de 1886 (Dublán y Lozano, 1887, pp. 662-669) retomó varios de los artículos de sus predecesores y los reestructuró en ocho capítulos. El primero dedicado a la definición y requisitos para establecer casas de empeño como licencias (renovables anualmente), patentes y locales. En cuanto al traslado y traspaso, el reglamento hacía hincapié en la necesidad de contar con licencia del gobernador de distrito bajo pena de multa y procesamiento legal en los tribunales correspondientes. El segundo

\footnotetext{
${ }^{11}$ EEM, 27-5-1886, p. 210.

${ }^{12}$ EEM, 29-7-1886, p. 313.
} 
capítulo, del contrato en los boletos, detallaba los datos que debían anotarse en los boletos y su registro en los libros talonarios. El capítulo tres, de las prendas, determinaba las características de su exhibición y su manejo al interior del local; al tiempo que estableció ciertas garantías a los prestatarios pues en caso de extravío o apropiación dolosa del objeto por parte del prestamista, este sería consignado a los tribunales. El capítulo cuatro trataba sobre los libros que cada casa debía llevar, ocho (diario, mayor, caja, entrada y salida de prendas, avalúos, movimiento, talonario) para las casas cuyo capital excediera de mil pesos y cuatro (entrada y salida de prendas, avalúos, movimiento, talonario) para aquellos cuyo capital fuese menor a aquella cantidad.

A diferencia de los reglamentos anteriores, el de 1886 puso especial interés en detallar las actividades de valuadores e interventores en los capítulos cinco y seis respectivamente. Los valuadores debían presentar una fianza de 2000 pesos y recibirían un sueldo de 1500 pesos anuales pagaderos con el producto del $5 \%$ impuesto por todo avalúo; mientras que los interventores recibirían un sueldo de mil pesos anuales del erario del ayuntamiento. Ambos empleados debían velar por el cumplimiento del reglamento en todas las fases del crédito, ya fuese en el avalúo o en el remate de las prendas. La novedad con respecto a los otros reglamentos es que al asignar sueldos fijos se esperaba que fungieran como un incentivo para evitar contubernio y malos manejos. De ahí que el siguiente capítulo estableciera lineamientos detallados para realizar los remates.

El capítulo ocho, prevenciones generales, contiene una novedad, ya que concedía "acción popular para que cualquier ciudadano denuncie ante el ministerio público o ante el gobierno del distrito los abusos de los dueños de empeños, de los valuadores e interventores" (p. 668) y dejaba en el gobernador de distrito la facultad de dirimir conflictos entre deudores y dueños de casas siempre y cuando el negocio no superara los 25 pesos.

Como es posible notar, aun cuando se acrecentó la vigilancia sobre la contabilidad y las operaciones de las casas de empeño, el gobierno no resolvió el problema de las altas tasas de interés. A decir de un observador de la época, otro de los principales defectos del reglamento era que la supresión de la fianza -mecanismo por el cual se aseguraba la prendaincurría en una mayor incertidumbre para el deudor por lo que era preciso reintroducir esa práctica pues "toca a las autoridades vigilar por la seguridad de las prendas y así lo reconocieron en diversas épocas varias administraciones proveyendo a la seguridad del público por medio de

RHAA v.56 n.1, 2021. ISSN: 0556-5960, ISSNe 2314-1549. CC BY-NC-SA 4.0 
fianzas proporcionales exigidas a los propietarios de las casas de empeño"13.

El crédito que otorgaron las casas de empeño no estuvo sujeto a una nueva reglamentación a lo largo del periodo aun frente a las necesidades de crédito entre el grueso de la población. Sumadas a estas instituciones también existían las sociedades de socorros mutuos, que a cambio del depósito de una cantidad ofrecían ayuda a sus agremiados en casos de enfermedad o urgencia, y las cajas de ahorros de trabajadores que retenían una parte del jornal susceptible de ser retirado en caso de enfermedad 0 retiro del empleo. A decir de Casasús (1890, p. 310) las cajas de ahorro tenían como principal ventaja el cultivo del ahorro entre los obreros, así como el potencial uso productivo del capital ya que, en caso de no tener emergencia alguna, los depósitos podrían ser utilizados en la creación de algún pequeño negocio.

Casasús mencionaba que la existencia de las sociedades de socorros mutuos, los montepíos y las cajas de ahorros de obreros no eran suficientes para ayudar al obrero, por lo que recomendaba la fusión de las cajas de ahorro con las sociedades de préstamo o montes de piedad en una nueva sociedad llamada sociedades de crédito prendario. Instituciones que tuviesen el papel de intermediarias entre los capitalistas y los obreros aprovechando el ahorro de éstos últimos en su beneficio. A decir de Casasús, estas sociedades habían tenido muy buenos resultados en Alemania pues lograban introducir el préstamo personal entre los trabajadores en aras de las mejoras en sus condiciones de vida.

Las recomendaciones de Casasús, sumadas al programa de José Yves Limantour para elevar la condición de los trabajadores de la Secretaría de Hacienda, fungieron como motivadores para el establecimiento en 1894 de la sociedad denominada "Caja de Ahorros y Préstamos para los empleados federales del ramo de Hacienda". En la elaboración del proyecto y los estatutos de la Caja, Casasús mencionó al secretario que en primer lugar no debía establecerse a la usanza francesa con el solo fin de acumular capital, sino con el objetivo de que el ahorro obtenido se utilizara para operaciones de préstamo con prenda o caución. Además, debía organizarse como una sociedad ajustada al Código de Comercio "para que sean dignas de llevar tal nombre y para que puedan ser personas morales distintas a los

${ }^{13}$ El Universal, México, 20-7-1888., p. 1.

RHAA v.56 n.1, 2021. ISSN: 0556-5960, ISSNe 2314-1549. CC BY-NC-SA 4.0 
asociados. Es decir, ya no debemos establecer sociedades mutualistas como las existentes, que son asociaciones, sino sociedades cooperativas"14.

Las recomendaciones de Casasús fueron escuchadas al pie de la letra pues según los estatutos de la Caja, las operaciones que podía realizar eran recibir depósitos con interés y realizar préstamos con interés garantizados ya con el sueldo recibido, prenda o fianza; a cambio, el trabajador recibía un título ejecutivo protegido por las leyes mercantiles. Para evitar el sobreendeudamiento y garantizar la participación de todo el personal, el mínimo de cada depósito era de un peso fuerte de plata y el máximo de 500 . Además, los préstamos respaldados con sueldo no podían exceder el triple mensual, los préstamos con prenda o fianza no podían exceder seis meses de plazo y los garantizados con caución no podían exceder el sueldo líquido correspondiente a tres meses. Finalmente, la tasa de interés no debía exceder el 5\% anual (Caja de Ahorros, 1900, pp. 1-44).

Sumado a los depósitos de los empleados, con la finalidad de aumentar el fondo de la caja, se le asignaron los ingresos provenientes de la totalidad del importe de las multas por corrección disciplinaria impuestas en las oficinas federales de hacienda y el $2 \%$ de las multas impuestas por infracciones a la Ordenanza de Aduanas y la ley del Timbre. Para asegurar el cumplimiento de esta disposición, el secretario ordenó en 1895 que todas las oficinas de hacienda remitiesen mensualmente un informe sobre las multas, cuyos importes debían ser enviados al tesorero de la Sociedad quien a su vez estaba obligado a situar los fondos en la Tesorería General de la Federación (Dublán y Lozano, 1898b, p. 40). Cabe mencionar que, si bien las acciones y dividendos estarían exentos de toda contribución federal, los contratos, recibos acciones y libros quedaban sujetos al pago del impuesto del Timbre.

Como es posible notar, las condiciones tanto de los préstamos como de la constitución misma de la Caja de Préstamos y Ahorros eran muy favorables para los empleados de Hacienda. En la Memoria de Hacienda de 1894-1895 Limantour informaba que la Caja había recibido $\$ 9906$ por réditos de las acciones, $\$ 500$ por donativos y $\$ 5355$ por remisiones en las oficinas por concepto de multas. Tal parece que la Sociedad tuvo el efecto esperado pues en el año de 1896-1897 sus ingresos se habían elevado a \$14179.82 y

${ }^{14}$ AJYL, Carta de Joaquín Casasús a José Yves Limantour, México, 15-10-1894, CDLIV.1a.1883.14.3562.

RHAA v.56 n.1, 2021. ISSN: 0556-5960, ISSNe 2314-1549. CC BY-NC-SA 4.0 
al siguiente año $\$ 22025.50$; lo cual estaba relacionado no sólo con el aumento de número de socios sino con el incremento del valor de sus acciones, ya que se elevó de \$25 en 1894 a \$51 en 1899. Hacia 1899 los estatutos de la Sociedad fueron reformados en aras de establecer límites en el número de acciones que cada socio podía adquirir, así como limitar el plazo de los préstamos a nueve meses, esto con el objetivo de no comprometer demasiado sus emolumentos y evitar el endeudamiento eterno (Quintanar, 2017, pp. 100-101).

Los resultados de la Caja de Ahorros y Préstamos de la Secretaría de Hacienda inspiraron la creación de instituciones del mismo tipo como la Sociedad Caja de Ahorros "Unión y fuerza" en Saltillo, Coahuila. La caja reunió a varios empleados federales -en su mayoría telegrafistas, de hacienda, timbre, correos y algunos otros del gobierno del estado- y realizaba préstamos con un $1 \%$ de interés tanto a particulares como a sus socios. Según Juan Carlos Covarrubias, el presidente de la sociedad, la caja había tenido utilidades mayores de mil pesos en sus primeros meses de operación, por lo que mencionaba a Limantour que estaban dispuestos a fungir como corresponsales de la Caja de Ahorros y Préstamos de la Secretaría de Hacienda ${ }^{15}$.

La oferta de crédito dirigida a las clases populares y trabajadoras durante el Porfiriato era muy limitada y el costo del dinero resultaba muy oneroso debido a las altas tasas de interés impuestas por los prestamistas. Entre las estrategias del gobierno porfiriano para evitar los abusos y fomentar el ahorro entre los sectores populares se encuentran una serie de medidas encaminadas a regular los préstamos de las casas de empeño y a ofrecer préstamos prendarios mediante el establecimiento de sociedades cooperativas, cuyo primer ensayo fue la Caja de Ahorros y Préstamos de la Secretaría de Hacienda.

La legislación sobre los bancos prendarios fue materia de discusión en las Comisión elaboradora de la Ley General de Instituciones de Crédito de 1897. Las alternativas analizadas para proveer de crédito a las clases populares fueron el establecimiento de sociedades de anticipos alemanas y las sociedades de crédito prendario, dado que las primeras no habían tenido el éxito esperado se optó por transformar los Montes de Piedad en

${ }^{15}$ AJYL, Carta de Juan Carlos Covarrubias a José Yves Limantour, Saltillo, 26-31895, CDLIV.1a.1883.16.4190.

RHAA v.56 n.1, 2021. ISSN: 0556-5960, ISSNe 2314-1549. CC BY-NC-SA 4.0 
instituciones de crédito reconocidas y legalizadas con el fin de eliminar las casas de empeño y cultivar el ahorro productivo, por lo que también funcionarían como cajas de ahorro. El capítulo VI del proyecto de ley presentado regulaba las sociedades de crédito prendario al definir que éstas debían establecerse en nombre colectivo si el capital social no excedía de cien mil pesos, en caso de que fuese establecida como sociedad cooperativa, debía establecerse con responsabilidad ilimitada y solidaria de parte de los socios. El capital mínimo con el que debían establecerse sería de $\$ 50000$ y sólo estaban facultades a realizar las siguientes operaciones: préstamos con garantía prendaria (muebles o alhajas), recibir depósitos con interés y emitir títulos que comprobaran el importe de los depósitos. Los préstamos otorgados no podían exceder la mitad del importe de la prenda y su plazo máximo sería de seis meses. El tipo de interés de todas aquellas operaciones no debía exceder del 1\% mensual, mientras que los depósitos devengarían in interés del $6 \%$ anual. Finalmente estaban obligadas a publicar sus balances registrando el capital social, el importe de las operaciones prendarias, la existencia en caja de dinero efectivo y el importe de los depósitos (Casasús, 1890, pp. 403-407).

Aun cuando la Comisión reglamentó el interés de los títulos, el remate de bienes y los bienes susceptibles de ser otorgados en prenda, sus propuestas no fueron integradas a la Ley general, a decir de Limantour esta decisión se debió a

(...) la conveniencia que hay en hablar por separado de operaciones que son de muy distinta índole que las que practican comúnmente las tres clases de banco arriba expresadas. Con el tiempo, aprovechado la experiencia que se adquiera y en la oportunidad más precisa, se complementará la obra comenzada (SHCP, 1909, p. 100).

La ocasión no llegó, al menos durante el gobierno porfiriano, por lo que la población mexicana siguió acudiendo a sus tradicionales formas de financiamiento para complementar sus medios de subsistencia.

\section{Consideraciones finales}

El sistema crediticio durante el Porfiriato estaba integrado por una diversidad de instituciones que atendían las necesidades financieras de la agricultura, minería y comercio. En los primeros años del periodo existían algunos bancos en los estados norteños formados principalmente por las familias empresariales más poderosas de la región. Estas instituciones 
coexistieron con instituciones de crédito no bancarias que aun con el establecimiento de un sistema de pluralidad bancaria con la Ley General de Instituciones de Crédito no cesaron sus operaciones, ya que el acceso al crédito bancario estaba limitado a la pertenencia o no de redes clientelares y de parentesco. Las casas mercantiles entonces tuvieron un papel de complementariedad ante las necesidades de crédito de los distintos agentes económicos.

Los estudios sobre el crédito a finales del siglo XIX, si bien analizan detalladamente la relación de la banca con el proceso de crecimiento económico del país, han dejado de lado los estudios de otras fuentes de crédito más allá de las casas mercantiles y los bancos estatales surgidos a partir de la ley de 1897. El análisis de las operaciones y el funcionamiento interno de instituciones de crédito no bancarias como los bancos sin concesión, los almacenes generales de depósito, las casas de empeño y las sociedades cooperativas ha sido una asignatura pendiente en la historiografía del crédito porfiriano.

A lo largo del presente artículo se ha visto el importante papel que aquellas instituciones tuvieron en la dotación de crédito para el comercio y las clases populares. Los Almacenes Generales de Depósito agilizaron el comercio en buena medida por las operaciones de pignoración que desarrollaron, de ahí que se constituyeran como una opción más para el crédito al comercio externo, sumada a la ya dada por los bancos legalmente establecidos. En cuanto al crédito prendario, como es posible notar, no contó con una ley particular que delimitara sus operaciones. No obstante, durante el periodo estudiado es posible notar que hubo un interés en controlar y vigilar las condiciones de los préstamos que otorgaban estas instituciones debido a que las principales preocupaciones al respecto eran la usura y el empobrecimiento que causaban sus altas tasas de interés. La finalidad de las sociedades de crédito prendario era velar por el beneficio de las clases populares usualmente marginadas de los bancos legalizados. Con la anterior es posible decir que la diversidad de las instituciones crediticias porfirianas deja de manifiesto que convivieron formas modernas y tradicionales de prestar y pedir prestado. 


\section{Bibliografía}

Aguilar, G. (2003). El sistema bancario en Sinaloa (1889-1926). Su influencia en el crecimiento económico. En M. Cerutti y C. Marichal (Comps.). La banca regional en México (1870-1930). El Colegio de México, Fondo de Cultura Económica, pp. 47-100.

Barrera Lavalle, F. (1909). Estudios sobre el origen, desenvolvimiento y legislación de las instituciones de crédito en México. Tipografía D. García y Cía.

Caja de Ahorros y Préstamos de los empleados federales del ramo de Hacienda (1900). Decretos de concesión, reformas y estatutos reformados. Tip. Ofna. Imp. del Timbre.

Casasús Joaquín D., (1890). Las instituciones de crédito. Estudio sobre sus funciones y organización. Tip. de la Secretaría de Fomento.

Cerutti, M. (1994). Crédito y transformaciones económicas en el norte de México (1850-1920): gran comercio, banca e industria en Monterrey. En P. Tedde y C. Marichal (Coords.). La formación de los bancos centrales en España y América Latina (siglos XIX y XX) vol. 1: España y México (pp. 179-221). Banco de España.

Cerutti, M. (1999). La expansión del crédito prebancario: diferencias regionales. En L. Ludlow, L. y J. Silva Riquer (Coords.). Los negocios y las ganancias de la colonia al México moderno (pp. 297-329). Instituto Mora.

Cerutti, M. y Marichal, C. (Comps.) (2003). La banca regional en México (1870-1930). El Colegio de México, Fondo de Cultura Económica.

Dublán M. y Lozano, J. M. (1882). Legislación Mexicana. Imprenta del Comercio de E. Dublán y Comp., t. XII.

Dublán M. y Lozano, J. M. (1886). Legislación Mexicana. Imprenta del Comercio de E. Dublán y Comp., t. XIII.

Dublán M. y Lozano, J. M. (1887). Legislación Mexicana. Imprenta del Comercio de E. Dublán y Comp., t. XVII.

Dublán M. y Lozano, J. M. (1898a). Legislación Mexicana. Imprenta del Comercio de E. Dublán y Comp., t. XXIII.

Dublán M. y Lozano, J. M. (1898b). Legislación Mexicana. Imprenta del Comercio de E. Dublán y Comp., t. XXV. 
Dublán M. y Lozano, J. M. (1904). Legislación Mexicana. Talleres tipográficos de Arturo y Alfredo G. Cuba., t. XXXII.

Gómez, M. (2003). El crecimiento de la banca local de emisión en México, 1897-1910. En M. Cerutti y C. Marichal (Comps.). La banca regional en México (1870-1930) (pp. 321-345). El Colegio de México, Fondo de Cultura Económica.

Gómez, M. (2011). Había una vez una vez un sistema de bancos privados emisores de billetes. México, 1897-1910. Historia Mexicana, LX (4), 2069-2109.

Grijalva Díaz, A. I. (2016). Banca, crédito y redes empresariales en Sonora, 1897-1976. El Colegio de Sonora.

Gurza, J. (1905). Nuestros bancos de emisión. Imprenta Central.

Kuntz, S. (2007). El comercio exterior de México en la era del capitalismo liberal, 1870-1929. El Colegio de México.

Levy, J. (2012). The making of a market. Credit, henequen and notaries in Yucatán, 1850-1900. The Pennsylvania State University Press,

Ludlow, L. (2006). Constitucionalistas y pragmáticos frente a los privilegios bancarios (1880-1889). En M. E. Romero Sotelo y L. Ludlow (Coords.), Temas a debate. Moneda y banca en México 1884-1954 (pp. 13-52). Universidad Nacional Autónoma de México.

Ludlow, L. (2003). El Banco Mercantil de Veracruz (1898-1906). En M. Cerutti y C. Marichal (Comps.). La banca regional en México (18701930) (pp. 134-167). El Colegio de México, Fondo de Cultura Económica.

Ludlow, L. (1998). La formación del Banco Nacional de México: aspectos institucionales y sociales. En L. Ludlow y C. Marichal (Coords.). La banca en México, 1820-1920 (pp. 142-180). Instituto Mora.

Macedo, P. (1905). La evolución mercantil, comunicaciones y obras públicas, la hacienda pública. Tres monografías que dan idea de una parte de la evolución económica de México. J. Ballescá y Cª editores.

Marichal, C. (1999). De la banca privada a la gran banca. Antonio Basagoiti en México y España, 1880-1911. Historia Mexicana, XLVIII (4), 767793.

Marichal, C. (2007). El despegue de un campo de estudio: historia del crédito y la banca en México (1820-1920). En F. Bourillon, P. Boutry, RHAA v.56 n.1, 2021. ISSN: 0556-5960, ISSNe 2314-1549. CC BY-NC-SA 4.0 
A. Encrevé, B. Touchelay, Des économies et des hommes. Mélanges offerts à Albert Broder, (pp.83-94). Institut Juan Baptiste Say, Université/Éditions Biére.

Marichal, C. y del Ángel, G. (2003). Poder y crisis: historiografía reciente del crédito y la banca en México, siglos XIX y XX. Historia Mexicana, LII (3), 677-724.

Maurer, N. (2002). The power and the money. The mexican financial system, 1876-1932, Stanford University Press.

Maurer, N. y Haber, S. (2007). Related lending, and economic performance: evidence form Mexico. The Journal of Economic History, 67 (3), 551581.

Olveda, J. (2003). Banca y banqueros en Guadalajara. En M. Cerutti y C. Marichal (Comps.), La banca regional en México (1870-1930) (pp. 291-320). El Colegio de México, Fondo de Cultura Económica.

Quintanar Zárate, I. (2017). La transformación del Estado liberal durante la gestión hacendaria de José Yves Limantour (1892-1911). Tesis de doctorado. El Colegio de México.

Rodríguez López, M. G. (2003). Paz y bancos en Durango durante el Porfiriato. En M. Cerutti y C. Marichal (Comps.), La banca regional en México (1870-1930) (pp. 254-290). El Colegio de México, Fondo de Cultura Económica.

Secretaría de Hacienda y Crédito Público (1900), Memoria de las Instituciones de Crédito correspondiente a los años de 1897, 1898 y 1899. Tipografía de la oficina impresora del Timbre, t. II.

Secretaría de hacienda y Crédito Público (1905). Memoria de Hacienda y Crédito Público presentada por el secretario de Hacienda José Y. Limantour al Congreso de la Unión correspondiente al año económico del 1 de julio de 1901 a 30 de junio de 1902. Tipografía e imprenta de la oficina impresora de estampillas.

Secretaría de Hacienda y Crédito Público, (1909), Instituciones de crédito. Leyes y circulares relativas, $3^{\underline{a}}$ ed, Tipografía de la oficina impresora de estampillas. 